\title{
Partners at Paris? \\ Climate Negotiations and Transatlantic Relations
}

\section{Introduction}

\section{Mai’a K. Davis Cross}

Since at least the early 1990s, the European Union (EU) has been a leader in seeking the creation of a legally binding, international climate regime. By contrast, the United States (US) has been steadfast in its opposition to this with its critical mass of "climate-change deniers" and lack of significant congressional support (Vogel 2012). Despite this, the US took much of the credit for negotiating the 2015 United Nations climate agreement in Paris (COP 21) with President Obama and Secretary of State John Kerry framing it as an American achievement after the fact. To add to this perception, the international media, with its typically Eurosceptic slant, largely framed it this way too (Cross 2017). But was this an accurate portrayal? And what can the Paris agreement tell us about the nature of the transatlantic relationship when it comes to the climate change crisis? While it may seem at first glance that the US led the world - with some help from France (as the media depicted it) - to a common agreement in 2015, this article explains how and why the climate agreement, if anything, was actually a European achievement. I argue that the climate crisis has ultimately strengthened the EU as an actor independently from, and to some extent in competition with, the US. With respect to the framework of this special issue, US recalcitrance in environmentalism has brought Europeans closer together, solidifying the EU's emergence as a leading global power in the realm of climate change policy (Riddervold and Newsome, 2018).

As an indication of the US's ephemeral support of the Paris agreement, and climate change regimes in general, any progress that was made under the Obama presidency quickly unraveled once Trump took office. Of course, EU member states have not been completely 
without divisions of their own, but this has been mainly a matter of degree. EU leaders are all committed to reducing emissions by at least $40 \%$ compared to 1990 by 2030 (80-95\% reduction by 2050). As will be described in this article, to the extent that the US influenced the agreement it was mainly to ensure that carbon reduction promises would not be binding and that everyone signed on to it (i.e. a lowest common denominator outcome). The US claimed a major "success," but in reality, behind the scenes the US did everything it could to weaken the terms of the deal (Dimitrov, 2016 p. 3). By contrast, even though it would have been impossible for the EU to get its ideal outcome - a binding agreement - the EU was successful in creating the context for more ambitious terms because it paved the way for countries to have the capacity (i.e. infrastructure, legal underpinning, and political will) to do so, and was remarkably skilled at negotiating a strong outcome during the final days of the summit itself.

Why was the EU able to do this? After all, for a long time the EU has been a relatively weak norm entrepreneur externally when it comes to environmental protection, even while binding itself to strong norms internally. The need to address the climate change crisis has been relatively uncontroversial in Europe, and a top priority in terms of the EU's external relations, but as Joseph Nye points out, "when Europeans went to the 2009 Copenhagen climate summit, the soft power of their superior domestic example on climate was not effective...its lofty aspirations were too far from the limited bargains being struck by other countries (Nye 2011, 98)." If the EU has struggled to have an impact through its climate diplomacy externally why was it finally able to increase its influence at the 2015 Paris summit?

With an epistemic communities framework, I trace the development of the EU's climate diplomacy, and examine the case of the Green Diplomacy Network. I argue that while the EU's climate diplomacy has underperformed in the past, it was quick to adapt and grow since the 2009 
Copenhagen summit through effectively broadening its epistemic community of climate diplomats, and through a process of political learning that ultimately led to stronger mutual recognition among actors (Eriksen 2016). ${ }^{1}$ Moreover, by getting others to join the EU in its efforts, the US could no longer afford to overtly drag its feet on the level of ambition, such as aiming for a target of less than $1.5^{\circ} \mathrm{C}$ increase in temperature compared to pre-industrial levels (in private, the US did not even want to agree to a limit as high as $2^{\circ} \mathrm{C}$ ). Scholars have documented the existence of numerous environmental epistemic communities, especially in Europe. However, when it comes to external influence in recent years, I argue that the climate diplomacy epistemic community has markedly grown in influence, leading to a breakthrough at the 2015 summit. $^{2}$

The EU's explicit strategy was to sharpen its narratives about the need for more ambitious climate policies worldwide, to reduce uncertainties about costs and fears in third countries, and to convince foreign audiences through active engagement in public diplomacy.

\section{Epistemic Communities as Norm Entrepreneurs}

The story of the US's involvement in climate change negotiations is relatively straightforward. The country has been an obstruction to global action to stop climate change for the better part of three decades, while continually taking credit for any minor advancements that are achieved at the international level. In this sense, the US is janus-faced: American representatives go to the negotiating table during major summits with the primary aim of

\footnotetext{
${ }^{1}$ Mutual recognition is defined as a process of deliberation that takes into account the diversity of circumstances and interests of all involved through a process of deliberation rather than relying on universal principles of justice (impartiality), ignoring others' non-compliance with norms (non-domination), or forcing others to comply with common rules (domination) (Eriksen 2016).

${ }^{2}$ Field research for this paper is partly based on my attendance as an official observer at the December 2015 UN

Framework Convention on Climate Change, and visit to India in November 2017.
} 
preventing any binding initiatives, while then claiming "success" at getting all countries to sign on to what is inevitably a weaker agreement as a result (Clémençon 2016). To the extent that the US is willing to support certain climate initiatives, it maintains a strong neoliberal stance, advocating for a pro-business cap-and-trade policy as opposed to a carbon tax, which would give governments revenue to invest in renewable energy and conservation. Whatever the administration in the US, the goal is also to prevent being disadvantaged by historical or equity considerations vis-à-vis developing countries, and to allow businesses to continue profiting regardless of the environmental consequences (Clémençon 2016). Thus, US policymakers have not been actively engaged in paving the way to an international climate agreement, but they do tend to play a highly visible role at major UN summits, even if only to ensure that the outcome is weak. It should go without saying that just because the US facilitates arrival at a common agreement does not mean that this constitutes a "success." Given what is at stake in this climate crisis, the actual quality and ambition of the agreement itself is what determines success.

The story on the EU side is far more complex because mitigating climate change is a major initiative for EU representatives both during and in preparation for major summits. However, much of the scholarly literature about the EU as an environmental actor focuses on the nitty gritty of the EU's role at specific climate summits instead of in the periods between these critical junctures. Climate change is now mainstreamed into all of the EU's dealings with third countries, but knowledge about the EU's green diplomacy over time is actually pretty limited. There is sometimes an assumption that these processes of diplomacy are not as important as the power and interest dynamics among the major players, and this tends to exaggerate the role of countries like the US and China. For example, Jon Hovi, Tora Skodvin, and Stine Aakre (2013) write, "Considering that the delegations to the UNFCCC Conferences of the Parties consist of 
highly skilled experts and diplomats, it is unlikely that insufficient knowledge of the problem at hand or lack of innovative proposals for an effective design of the international climate regime explains the lack of progress." However, I argue that it is not so much the lack of knowledge among diplomats and experts, but the longer-term policy strategies they engage in such as through laying the ground-work in advance of the summits, persuading others through effective narratives, and increasing the size and scope of their shared epistemic community over time. Thus, to understand the strengths or weaknesses of the EU's influence at summits, it is necessary to also consider what EU diplomats do in the years leading up to major summits. This is where the EU is highly active, while the US is not.

Before I address why an epistemic communities framework is helpful in this regard, it is helpful to first review the debate in the literature surrounding the role of the EU in climate diplomacy. The main question much of the literature addresses is: Why has the EU seemingly underperformed when it comes to convincing others to agree to the formation of a single, binding international climate regime? One perspective is that EU member states have actually not been as cohesive internally as it would seem. In the 1990s and the early years of the $21^{\text {st }}$ century, we can clearly observe increasing unity of climate goals across EU member states (Oberthur 2011). However, at the 2009 Copenhagen summit, Lisanne Groen and Arne Niemann $(2011,10)$ argue that there were key differences across member states that were masked by the draft text, but that came through in the negotiations themselves. To name just one example, the well-known European promise at the time to reduce emissions by $30 \%$ compared to 1990 levels by 2020, on the condition that other developed countries matched that goal, was actually still contested by some member states in the lead up to Copenhagen (Groen and Niemann 2011, 10-11). Indeed, some member states - Netherlands, the UK, Germany, France, Denmark and Sweden - were 
more progressive in their stances while others were resistant - Italy, Poland, Bulgaria, Estonia, Hungary, Latvia, Lithuania, Romania and Slovakia - and this gap was far more apparent when heads of state are at the negotiating table. Thus, the argument is that internal cohesion had not yet been fully achieved, and this backfires if the groundwork before major summits is not clearly laid. At the same time, others have made convincing cases that the EU has actually been highly unified and cohesive in terms of external environmental positions (for example, see Schaik 2009, Haug and Berkhout 2010).

Another perspective, which constitutes the bulk of the literature, argues that the EU suffers from weak external influence in getting other major actors on board, especially the US and China, because of shifting international geopolitics (Haug and Berhout 2010; E3 2010). As Sebastian Oberthur $(2011,677)$ argues, the EU increasingly controls a smaller portion of global greenhouse gas emissions - around $10 \%$ - and so there is a limit to what the EU can do on its own. China and the US together account for $40 \%$ of emissions. The less developed world, if China is included, produces the majority of carbon emissions. Another key aspect of these changes in the international system is that the EU has been losing its leadership status to the US, especially during the Obama presidency and the 2009 Copenhagen summit. While the US had previously withdrawn from leadership when it came to the Kyoto Protocol, under Obama's presidency the US was much more involved in shaping a new international climate regime, further detracting from the EU's ability to distinguish itself as a leader in this area. The argument is that as a result of this the EU has been thrown into a mediator role rather than maintaining its previous leadership role (Backstrand and Elgstrom 2013). Backstrand and Elgstrom (2013) argue that this shift became particularly apparent after the EU was marginalized in 2009 at the Copenhagen summit. They argue that the EU's weight in the world when it comes 
to cooperation on climate has diminished because of "transformations in aggregate and issuespecific structural power" (Ibid 2013, 1373). The US and China are often viewed as veto players for any climate deal, reducing the ability of the EU to do anything but mediate.

A third perspective is that the EU has actually been a strong norm entrepreneur, but just not when it comes to achieving far-ranging agreements that may require a degree of moral commitment to saving the planet. In other words, this perspective argues that the EU is very powerful when it comes to its regulatory framework because this is connected to access to its common market (Vogel 2012; Keleman and Vogel 2009). But outside of its internationally powerful regulatory influence, the EU falls short (Schaik and Schunz 2011). Climate summits are different from exporting domestic regulation because these are critical junctures in which the EU seeks to convince other countries to adopt far-reaching policy change that go beyond the technical requirements for access to the EU's internal market. Thus, the argument is that the EU has been relatively successful in influencing others to make smaller, technical changes in order to have access to its market, but not in making larger, moral-driven changes to safeguard the future of the planet.

While each of these three perspectives certainly captures various aspects of the EU's external influence when it comes to climate policy, they also tend to bracket out processes among professional diplomats with climate expertise. I argue that these diplomats are actually central to persuading others to change their behavior, and important actors to understand in their own right. As the EU becomes more unified in its stance on climate, and the crisis becomes ever more pressing, what diplomats do in the lead up and during major climate negotiations can make or break a final agreement. In particular, there has been an important trend in the nature of the EU's climate diplomacy since 2009 when the EU failed to exert influence on the outcome at the 
Copenhagen climate summit. Since then, there has been a political learning process in which diplomats have become increasingly effective at laying the groundwork for international agreements. In particular, they have become better at recognizing and incorporating the distinct local challenges that countries face. Political learning is defined as changes or adaptations in "strategies for advocating policy ideas" (May 1992, 339) in response to past policy experiences or failures. Oftentimes such learning is not entirely directed or planned, but more about trial and error, and it is distinguished from policy learning, which is about changing the underlying goals. Since Copenhagen, the EU has been engaging in bridge building and coalition building with third countries, especially in the developing world, but it has not changed its main goal of global reduction of carbon emissions (Backstrand and Elgstrom 2013). There is evidence that those engaged in climate diplomacy have augmented, as Peter May $(1992,339)$ puts it, "their awareness of the relationship between the political strategy they employ and its impact on the political prospects for a given proposal being enacted, they become more sophisticated in their policy advocacy." Moreover, these changed practices and strategies are in line with theories of epistemic community formation, cohesion, and expansion.

Epistemic communities are networks of experts who persuade others of their shared norms and policy goals by virtue of their professional knowledge. Thus, they are a prime example of norm entrepreneurs. Their reliance on shared expertise is what differentiates them from other actors that seek to influence policy. This expertise need not necessarily be derived from hard science, as knowledge in environmental law or disaster response, for example, is no less expertise-driven than knowledge in environmental science or biology (Cross 2013). However, epistemic communities' policy goals must derive from their members' expert knowledge, not some other motivation, otherwise they may lose authority with their target 
audience. Epistemic communities are recognized as key actors in transnational global governance, especially environmental governance, and they are a major means by which knowledge translates into power. Epistemic communities not only craft specific government policies, but also shape environmental governance more broadly.

It is important to recognize that epistemic communities can be comprised of diplomats, particularly when a network of diplomats has a claim to a specific kind of shared knowledge as is the case with those focused on climate issues (Cross 2007, 2011). Two reasons that diplomats have not typically been considered epistemic communities is that they are obliged to represent national interests and that they seem to be generalists rather than experts. Nevertheless, there is much to suggest that formal groupings of diplomats often transcend their prescribed role, and routinely operate as an epistemic community. Diplomats are experts at the art of negotiation, persuasion, and compromise. Their internal processes of deliberation and the professional norms that govern these processes are so important that they determine the success or failure of potential international agreements.

\section{EU Climate Diplomacy \& The Green Diplomacy Network}

The EU clearly surpassed the US in taking the lead on the climate change issue around the time of the 1992 Rio "earth summit," and this role was further consolidated with the subsequent 1997 Kyoto Protocol (Vogel 2012, 6). Despite a lack of US leadership, the EU subsequently led the implementation of the Kyoto Protocol. As time went by, EU member states became increasingly unified in their stance at climate negotiations, making it easier for them to speak with one voice internationally. In contrast to the more intergovernmental case studies in this special issue, EU environmental policy has become one of the most supranational areas of 
policymaking, especially since the 2009 Lisbon Treaty made it a legal requirement for the EU to pursue sustainable development in all of its relevant policies. However, as Diarmuid Torney (2013) argues, the more unified the EU became, the more it was characterized as having a "bunker mentality," in that others felt EU member states were too much involved in talking to each other. The goal of the EU's climate diplomacy today is to build an international regime that will achieve solutions to climate change, an $80 \%$ or more reduction in carbon emissions globally by 2050 , and zero carbon emissions by around 2060-2080. These solutions go beyond simply persuading others to have the ambition to reduce carbon emissions, but also finding the processes by which this ambition can be fulfilled. A pre-requisite for successful climate diplomacy is to understand other countries' perspectives (Mabey, Gallagher and Born 2013, 14). This includes a process of building "trust, mutual understanding and a sense of common endeavor" (Ibid. 22). The EU explicitly recognizes that the means of achieving this is through the creation of common narratives and consistent messaging.

In 2003, the EU launched the Green Diplomacy Network to enable a higher positioning of environmental issues in the EU's foreign policy, and consolidation of member states' and the Commission's approach. As the EU describes it:

The EU Green Diplomacy Network (GDN) is a flexible, informal and innovative tool that works towards a better integration of the EU environment policies into external relations practices. The GDN uses the EU Member State and Commission's extensive diplomatic networks to provide an effective means of gathering and exchanging information (EEAS 2017). ${ }^{3}$

The aim is to take a bottom-up approach and for the EU to speak with one voice when it comes to climate issues. The network is central to gathering the intelligence needed to understand other

\footnotetext{
${ }^{3}$ European External Action Service, "Environment and Climate Change," http://www.eeas.europa.eu/environment/gdn/index_en.htm
} 
countries' perspective, and to figure out how to engage in effective outreach or public diplomacy (EEAS and Commission 2013).

In contrast to the multilateral UN summits, the Green Diplomacy Network is comprised more of numerous bilateral cooperative initiatives between the EU and third countries. The EU's top priorities in terms of these bilateral relationships are China, India, and South Africa. Other priority partnerships are with the US, Canada, Japan, Australia, and Brazil. In the early years of its existence, the Green Diplomacy Network (2005a, 2005b, 2006) was particularly active in the areas of sustainability, maintaining biodiversity, and preventing environmental damage from toxic chemicals. Once these bilateral ties were more established, the Green Diplomacy Network held informal gatherings involving multiple countries with similar goals and interests. For example, in 2004, the EU launched a climate change demarche involving 34 third countries (General Secretariat of the Council 2005). In 2005, the Council assessed its early achievements, and concluded that this constituted a major aspect of early success. However, these initiatives were not ultimately enough to achieve overarching EU goals in the area of climate degradation.

In the beginning, the country that held the rotating presidency was also in charge of setting the goals of the Green Diplomacy Network, but after the 2009 Lisbon Treaty, the network came under the EEAS's purview. This meant that the success of this diplomatic initiative became less reliant on the capabilities of whichever country happened to be representing the EU. Relevant European commission DGs are also involved, especially DG Development and DG CLIMA, as well as member states representatives, and individuals in third countries nominated by the EU. There emerged more of an emphasis on growing and strengthening this network.

Since the 2009 Lisbon Treaty, and based on the lessons of the 2009 Copenhagen summit, the EU "re-launched" the Green Diplomacy Network and revised its diplomatic strategy. The 
EU tends to rely on making promises at UN summits to go further and pay more than others to stop climate change, in the hope that they will follow suit, but this has not been very effective on its own. This was most apparent at the 2009 Copenhagen summit where the EU was clearly sidelined. Many subsequent analyses of this summit argue precisely that the EU's narrative of leading by example or extending its own preferences to others, had to change in time for Paris 2015. As part of its diplomatic "re-thinking," the EU tried to focus more on recognizing the normative viewpoints of third countries. Through its epistemic community of diplomats it also tried to follow through much more committedly with its pragmatic, bottom-up approach. Subsequently, the EU regained some influence in 2011, in setting up the so-called Durban Platform, which required a major climate agreement among international players by 2015 so that it can be implemented by 2020 when Kyoto expires. With the Durban Platform, it was clear that the EU viewed the December 2015 Paris summit as a make or break moment. All climate diplomacy efforts were mobilized to try to ensure that the summit would be ground breaking.

Thus, 2009 was a critical juncture for the EU's climate influence in two respects. First, the EU learned from its failure at the Copenhagen summit, and second, it agreed to the Lisbon Treaty, which significantly enhanced the EU's diplomatic potential more generally through the advent of the European External Action Service. Since these events, the EU noticeably ratcheted up the scope and scale of its climate diplomacy, indicating that strategic learning had taken place. In the period from 2009 to the end of 2016, the EU made a much more concerted and strategic effort to prepare for the 2015 summit compared to before (Nelsen 2015).

To name some examples of this, EU diplomats thoroughly integrated climate change into its Policy Dialogues with developing-world partners. Among other things, the EU created the Global Climate Change Alliance (GCCA), and held a special conference in Brussels in 
September 2012, a Global Learning Event. The GCCA supports and provides programs in at least 27 countries and regions around the world. One of the key goals for EU climate diplomats has been to help national development processes incorporate climate change from early on.

This effort is particularly targeted in Africa, where many of the world's Least Developed Countries are located. On this continent, building resilience to the effects of climate change is most challenging. The Africa-EU Strategic Partnership on Climate Change and Environment is a major part of the EU's climate diplomacy in the region, and the EU is even sometimes involved in the African Environment Ministries (AMCEN) process (European Commission 2012). In 2011, this outreach effort expanded to incorporate the Caribbean Community. The EU began to provide significant financial support to the Caribbean Community Climate Change Centre. Alongside this, EU climate diplomats renewed the EU-Pacific relationship. The Commission and EEAS have also increased their direct engagement with countries in Latin America and Asia. They held an EU-Asia-Pacific roundtable in June 2012 with broad participation of environmental and development leaders to discuss climate change and how EU policies in the region can help. They held a similar, follow-up event in Africa in October 2012.

Such actions were intended to lay the domestic-level groundwork in third countries so that they were able to commit to international agreements at major summits, and participate in the creation of a climate regime to replace the Kyoto Protocol. As the European Commission put it:

Together with our partner countries, we seek to ensure that EU regular assistance is systematically integrating climate change considerations, from programming investments in social and physical infrastructure to national sector programmes. We are working to help strengthen countries' institutions and systems to integrate climate change in their development planning processes, from policymaking to budgeting, implementation and monitoring (European Commission 2012, 6). 
Essentially, by mainstreaming climate into all of the EU's Policy Dialogues, the EU hoped to mainstream climate in the government policies of these target countries (European Commission 2012, 6). In so doing, the EU significantly improved its recognition of the interests and concerns of third countries.

Since 2009, EU strategies have also involved mobilizing celebrities and tens of thousands of diplomats beyond Europe. The EU worked on solidifying promises and alliances by June 2015 in preparation for December 2015. This “diplomatic blitz," as the Guardian called it, really played on the strengths of the EU with its enormous diplomatic network (Nelson 2015). However, true to its market-driven justification, the EU's action plan states, "particular focus should be put on mobilising the private sector as a major source of financing and of innovation to tackle climate change" (Ibid.).

In the final lead up to the Paris summit, the EU laid specific emphasis on its climate diplomacy, and in particular, a Climate Diplomacy Action Plan developed by the EEAS and Commission. This plan included raising climate issues during any political dialogue at international institutions, supporting climate resilience in EU development policies, and linking climate change to long-term challenges (European Commission 2015, 12). Again, this amounted to mainstreaming climate diplomacy, and fostering epistemic communities of climate experts. Horizon 2020, the EU's largest research funding initiative to date, was linked to this too. At least $€ 28$ billion of Horizon 2020 funding was designated for climate related actions (Ibid.). More generally, "the EU has designated one-fifth of its entire budget up until 2020 to climaterelated policies and projects" (European Commission 2014).

The Council Conclusions on Climate Diplomacy emphasizes the need for a huge amount of advance work in the lead-up to the Paris summit. The Council writes, "there is a distinctive 
role for the EU and national diplomatic networks in promoting that partner countries adopt the domestic frameworks necessary to an ambitious global agreement" (Council of the European Union 2013, 2). In emphasizing the need for a mammoth effort in climate diplomacy the Council fell in line with the Commission and High Representatives proposal entitled, "An EU Climate Diplomacy for 2015 and Beyond," and its strategic toolbox approach for climate diplomacy. This included stronger diplomacy and lobbying to avoid surpassing $2^{\circ} \mathrm{C}$ temperature change through the creation of a single climate regime. In sum, this strategy entailed:

1. building commitment at the highest political levels

2. deepening bilateral contacts, especially in terms of helping partners develop domestic level policies that pave the way to international agreements

3. mainstreaming climate change when talking about security

4. building confidence internationally through political dialogue, public diplomacy, strategic advocacy

5. developing "mutually reinforcing positions in other international processes" (EEAS 2015,3 ) including coherent and unified narratives that link climate change to other policy goals

6. cooperating strategically with other countries that share the EU's level of ambition, nurturing this "coalition of ambition"

7. designing and implementing a climate diplomacy toolbox

EU diplomats in the Green Diplomacy Network have essentially been trying to persuade other states' diplomats to serve as norm entrepreneurs themselves in their own domestic contexts through using international arguments to influence their internal debates about the environment. This is akin to expanding the epistemic community of climate diplomats beyond Europe. As Martha Finnemore and Kathryn Sikkink $(1998,893)$ point out, domestic and international norms are firmly linked. This is especially true when it comes to climate policy since we are still at the early phase of a potential norm life cycle.

The process of influencing others requires strong diplomatic skills, and the ability to map out clear strategies that result in achieving the EU's climate goals. But beyond this, climate diplomacy requires strong and convincing messages. UN summits are significant opportunities 
for this, but preparation is required over time because the actual change has to happen at the domestic level. Since Copenhagen, the EU articulated a new strategy for its climate diplomacy. As described above, its strategy focused on communicating how serious of a problem climate change is and how it is linked to a number of other concerns such as security. Most of the strategy focused on engaging with different stakeholders, sharing information about risks, and providing training. By examining the narratives, processes, and results of the UN climate summit in Paris, it is possible to more fully understand the actual impact of this epistemic community of climate diplomats since the revamping of the EU's approach post-2009.

\section{The Impact of Climate Diplomacy on the Paris Summit, December 2015}

At past UN summits, the EU clearly pursued a narrative based on the argument that others should follow the EU's lead because it has worked out well for the EU. For example, the Commission $(2005,5)$ writes:

Although developing countries are more vulnerable than industrialised countries to the damages of climate change, they are concerned that reducing emissions will harm their economic development. However, the experience of the new Member States during the economic recovery in the second half of the 1990s shows that this needs not to be the case.

And the EU has offered to do more than other countries if only they would match the EU's level of reductions. In 2007, European Commission President Barroso promised that the EU would reduce emissions to at least $20 \%$ below 1990 s levels by 2020 , but would increase this to $30 \%$ if an international climate regime could be agreed by 2012. In 2014, the EU then unilaterally promised a reduction of $40 \%$ of 1990 levels by 2030 .

At Copenhagen, there are many reasons cited for why EU leadership fell short. However, as Peters $(2015,29)$ argues, the core pre-requisite was missing: offering a narrative that resonated with other states. Mutual recognition was absent. Peters (Ibid. 31) writes, "its 
narrative of leading by example, based in a discourse of ecological modernisation, retained a certain arrogance in its disregard for the climate policies already being undertaken by such countries, and a suspicion of the economic interests contained within the EU's liberalising ambitions." This was particularly true for India and China. ${ }^{4}$ The Paris summit, by contrast, showcased what is possible when the EU mobilizes its full diplomatic capacity to pave the way towards agreement.

At Paris, the EU conveyed a consistent message of ambition: that from 1990 to 2014 the EU reduced its emissions by $27 \%$ percent while growing its economy by $43 \%$ during the same period. ${ }^{5}$ In doing so, it was trying to counter the ongoing assumption on the part of developing countries at the summit that the two could not go hand-in-hand. It also got at the heart of what concerned developing countries from their point of view. Each EU representative ensured that this fact was part of each statement, at high-level and low-level meetings, indicating a purposeful attempt to coordinate messaging.

The EU and member states also played a strong role in setting the stage for the negotiations. Two of the biggest obstacles to getting developing countries to accept global climate agreements are fear of the unknown and misunderstanding about the nature of what they are signing on to (EU pavilion, COP 21, December 7, 2015). One of the most significant aspects of agreement in the lead up to COP 21 was that nearly all of the countries submitted Intended Nationally Determined Contributions (INDCs). This was described by many at the summit as "revolutionary" in nature, bringing this negotiation to a level far beyond Kyoto as it involved 185 countries, representing 96\% of global emissions (Cañete, COP21, December 7, 2015). Moreover, the EU played a significant role in ensuring that it was encouraging and facilitating

\footnotetext{
${ }^{4}$ Personal meetings with climate officials in India, November 2017.

${ }^{5}$ Participant observation, December 7-11, 2015 COP 21, Plenary and EU pavilion events.
} 
the creation of INDCs, which was actually a very technical and complex procedure to fulfill, especially among developing countries.

At the outset, the EU itself put forward an ambitious INDC (individual member states did not submit separate INDCs), and used this as leverage to challenge the US and China to do the same. This was more of a broad-level tactic to spur other state into action. However, the EU followed this up with careful and intensive work in dozens of third countries to help them prepare and submit their INDCs before the start of the climate summit. Alongside the EU, France and Germany had significant numbers of experts aiding in the effort (Panel at EU pavilion, COP21, December 8, 2015). The impetus to really go through with the INDCs, came rather late in the game - less than a year before the summit - and it was quite a challenge to ensure that as many as possible were submitted before November 30, 2015.

What was the EU's strategy on the ground in third countries? First, early on in the process, European Commissioner for Climate and Energy, Miguel Arias Cañete, and MinisterDelegate for the Environment Morocco, Hakima El Haite, held a special seminar in Rabat early on to discuss the upcoming process of INDC (which originally started as a lessons-learned from Kyoto) (EU Pavilion at COP 21, “High-level panel,” December 8, 2015). They didn't know what to expect because they thought other countries would see this as forcing them to comply. But the other countries were very positive. Second, after pioneering this effort early on, the EU set to work on helping developing countries through the technicalities of the process. In order to promise a precise percentage reduction of greenhouse gas emissions by 2020 , each country needed to be able to accurately calculate what they were currently emitting and what percentage reduction was realistic. The biggest challenge they faced was being able to measure and produce this kind of highly technical data (EU Pavilion at COP 21, "Practitioners Panel" December 8, 
2015). The EU, member states, and European NGOs sent experts to these countries to assist them in using the same methodologies that EU member states had used (Schafhausen, December 8, 2015). As one German practitioner put it, "we want to develop such a scheme all over the world, like in France and Germany. Some countries might need more time, but we still need the same methodology all around the world."

Third, the EU provided funding to NGOs to support local governments and cities in emerging economies to develop low emissions approaches from the start and also provide technical know-how such as "to improve institutional capacity to plan, act and monitor," and to take into account, "the local and national contexts are considered when developing tailor-made approaches" (Urban Low Emission Development Strategies , 2015).

For example, UN-Habitat and ICLEI (Local Governments for Sustainability) received $€ 6,700,000$ for the period March 1, 2012 to August 31, 2015 to pursue low emissions development. This EU funded project involved a focus on helping "model cities" in India, South Africa, Indonesia, and Brazil that would adopt these new policies with the help of practitioners and experts, based on European experiences and local conditions. They also designated "satellite cities" nearby that would further seek to implement these policies based on the model cities. Effectively, this created a South-South-North network of cities that would contribute to the achievement of INDCs of these countries overall (Ibid.).

Thus, the nature of the EU's impact on the ground involved both direct and indirect encouragement of greenhouse gas reductions through the combined use of transmitting EU best practices with close consideration of local circumstances and concerns. These initiatives were designed to be long-term. The EU certainly used itself as a model in terms of how to gather data and best practices, but it sets benchmarks according to local conditions. They followed a method 
of persuasion rather than bargaining, being careful to offer strong advice, but also realizing when to give in.

At the Paris climate summit, EU diplomats were the driving force behind the negotiations on many levels. It is important to note that all $28 \mathrm{EU}$ member states spoke with one voice throughout the negotiations. In other words, each diplomat from an EU member state represented the EU as a whole, creating a pervasive European influence throughout the summit venue. In particular, the EU conveyed a central and consistent message: economic growth and emissions reduction go hand-in-hand. This was part of each official statement, at high-level and low-level meetings.

Moreover, with the French delegation in charge of procedure for the entire summit, EU diplomats were able to achieve an effective combination of both flexibility in terms of diplomatic protocol, and efficiency in terms of reaching the final agreement. Much of this rested on small, informal gatherings of diplomats on the sidelines of the conference as well as secret bilateral communications among top decision-makers (Dimitrov 2016). Many diplomats and world leaders praised the French for their highly effective negotiating procedure, especially compared to the previously failed summit at Copenhagen. However, the European contribution did not just come from French diplomats, as news reports at the time assumed.

In the final days of the summit, the EU created what became known on the ground as the "high-ambition coalition." This coalition included the EU (and its 28 member states) as well as 79 African, Caribbean, and Pacific countries. While the United States hesitated to join this coalition, these countries announced their commitment to have:

- A legally binding and fair agreement

- Long-term ambition that responds to science

- A review mechanism to examine progress every five years

- Transparency and accountability in following through with carbon reduction commitment 
As EU Commissioner Miguel Arias Cañete said, “These negotiations are not about 'them' and 'us'. These negotiations are about all of us, both developed and developing countries, finding common ground and solutions together. This is why the EU and the African, Caribbean, and Pacific countries have agreed to join forces for an ambitious outcome here in Paris. We urge other countries to join us. Together we can do it. The EU stands shoulder to shoulder with its long term partners in the African, Caribbean, and Pacific regions." Two days after the announcement of the high-ambition coalition, the US was persuaded to join, along with Norway, Mexico, Columbia, and others. Well over 100 countries added their names to this coalition, and this paved the way to the first universal climate agreement. Alongside this, a majority of countries agreed (though unofficially) to limit global warming to $1.5^{\circ} \mathrm{C}$, instead of the original $2^{\circ} \mathrm{C}$. Even the latter did not sit comfortably with the US.

Ultimately, without the groundwork laid by the climate diplomacy epistemic community in the years leading up to the summit, such a strong coalition in the final days would have been unlikely. And without the widespread pressure that the EU was able to muster through this large coalition of countries, the US may have once more been able to fully weaken the agreement. While it is important to note that the agreement itself still falls short of the level of ambition required to prevent warming above 2 degrees, it represents a significant and unprecedented step in the right direction, and includes provisions for revising the level of carbon reduction over time so that more can be accomplished. Thus, the climate agreement was a success for the EU. The level of ambition and progressive nature of the Paris agreement would not have been possible without the influence of the EU, and was something the US was to some degree pressured into accepting. 


\section{Conclusion}

At Copenhagen, the EU lacked a political strategy, and as the environmental NGO E3G argues, European negotiators lacked diplomatic skills (E3 2010). Other noted problems include not being willing to openly criticize the US, a lack of discipline among the European representatives at the summit, not enough investment in pressuring China and India, not realizing the broader economic relationships at stake among the key players, and generally not adopting a tougher stance in demanding a binding agreement (Ibid., 7). In short, in a variety of ways, the EU fell short in understanding climate policy from the perspective of others, and this directly impacted its ability to be strategic in its diplomacy. The EU had strongly articulated goals, but not a good sense of how to achieve these goals.

Since the 2009 summit, it seems that the EU learned from its mistakes, and has ramped up its climate diplomacy efforts based on these lessons. Many studies focus on the importance of diplomatic capacity, technological know-how, and high-level buy-in from senior officials in home governments (Mabey, Gallagher, and Camilla Born 2013). The EU actively pursued these procedural goals in preparation for the 2015 Paris summit. In addition, through its diplomacy network, the EU achieved better mutual recognition among the key players, particularly in the developing world, taking into account local voices and circumstances. This has had important implications not only for the success of the Paris agreement, but also for the EU's global justice aims in its foreign policy more generally (Sjursen 2017). In other words, the ability of the diplomatic network to persuade also rested on a just approach in its relations with third countries.

I have argued that an epistemic community framework, alongside the concept of political learning, is helpful in understanding how the EU has improved its approach to climate diplomacy. The Green Diplomacy Network has enabled an expansion in membership of this 
epistemic community of diplomats, and has led to a snowball effect in which EU diplomats were able to show diplomats in third countries how to apply international norms domestically. By mainstreaming the climate issue and incorporating it into development policies domestically in third countries, this epistemic community laid the groundwork for an international level agreement. The outcome of the Paris summit demonstrates that such efforts were sufficient to bring the world from a norm emergence stage to a norm cascade. The evidence that political learning took place is clear: climate diplomats changed their political strategy, they called attention to the problem, they emphasized certain more successful policy arguments, and tried new tactics. Because of these processes, the EU is becoming a stronger actor in climate issues, especially given its need to counter the US.

The Green Diplomacy Network and epistemic community involved in climate diplomacy are on the rise in terms of influence and persuasiveness. But in the context of a new, antienvironment, climate-denying Trump Administration in the US, the ability to achieve these goals is getting far more challenging. The transatlantic alliance is now essentially non-existent in the realm of climate change. This is further strengthening the EU as a global leader in climate, and bringing member states closer together. But a weak transatlantic alliance exacerbates other factors, such as the ability to cooperate on informing the public through public diplomacy campaigns, helping developing countries understand the advantages of protecting the environment, and building a shared roadmap for how to achieve environmental protection on a political level.

\section{References}


Backstrand, Karin and Ole Elgstrom. 2013. "The EU's role in climate change negotiations: from leader to 'leadiator'," Journal of European Public Policy, 20(10): 1369-1386.

Cañete, Miguel Arias, Speech by European Commissioner for Climate and Energy, COP21, December 7, 2015.

Clémençon, Raymond. 2016. "The Two Sides of the Paris Climate Agreement: Dismal Failure or Historic Breakthrough?” Journal of Environment \& Development 25(1): 3-24.

Council of the European Union, "Council Conclusions on EU Climate Diplomacy," Foreign Affairs Council Meeting, Luxembourg, 24 June 2013. p. 2.

Cross, Mai'a K. Davis. 2013. "Rethinking Epistemic Communities Twenty Years Later,” Review of International Studies, 39(1): 137-160.

Cross, Mai'a K. Davis, The European Diplomatic Corps: Diplomats and International Cooperation from Westphalia to Maastricht, Palgrave, 2007.

Cross, Mai'a K. Davis, Security Integration in Europe: How Knowledge-based Networks Have Transformed the European Union, University of Michigan Press, 2011.

Cross, Mai'a K. Davis, The Politics of Crisis in Europe, New York: Cambridge University Press, 2017.

Dimitrov, Radoslav S. 2016. "The Paris Agreement on Climate Change: Behind Closed Doors," Global Environmental Politics 16(3): 1-11.

E3, "Building the 2c Coalition: European Climate Diplomacy after Copenhagen," E3 Discussion Paper, April 2010.

European External Action Service, "Environment and Climate Change," http://www.eeas.europa.eu/environment/gdn/index_en.htm 
EEAS and Commission, "EU climate diplomacy for 2015 and beyond: Reflection paper," Nonpaper, 2013.

Eriksen, Erik O. 2016. “Three Conceptions of Global Political Justice,” Globus Research Papers, November.

European Commission. 2005. 'Winning the Battle Against Global Climate Change', Communication to the Council, the European Parliament, the European Economic and Social Committee and the Committee of the Regions, Brussels, 9 February, p. 5.

European Commission. 2012. "Supporting a Climate for Change: The EU and developing countries working together."

European Commission. 2014. "Africa Climate Briefing," Publications Office of the European Union.

European Commission. 2015. "The Paris Protocol - A blueprint for tackling global climate change beyond 2020," Communication from the Commission to the European Parliament and the Council, Brussels, 25 February.

EU pavilion at COP21, December 8, 2015.

EU Pavilion at COP 21, "High-level panel: What needs to happen in Paris? A policy response to rise to the challenge," Paris, December 8, 2015.

EU Pavilion at COP 21, "Practitioners Panel: Learning from INDC preparations and accelerating implementation after Paris, December 8, 2015.

Finnemore, Martha and Kathryn Sikkink. 1998. "International Norm Dynamics and Political Change," International Organization, 52(4): 887-917.

General Secretariat of the Council to Coreper, "Green Diplomacy Network - Report on results achieved,” Brussels, 27 May 2005. 
Green Diplomacy Network. 2005a. "Environmental Sustainability: What is it and why is it important?," GDN's e-Brochures, 19 October.

Green Diplomacy Network. 2005b. "International chemicals issues,” GDN's e-Brochures, 19 October.

Green Diplomacy Network. 2006. "Maintaining ecosystem services and biodiversity: a prerequisite for human well-being," GDN's e-Brochures, June 16.

Groen, Lisanne and Arne Niemann, "EU actorness and effectiveness under political pressure at the Copenhagen climate change negotiations," Paper prepared for the Twelfth European Union Studies Association Conference Boston, Massachusetts, March 3-5, 2011. p. 10.

Haug, Constanze and Frans Berkhout. 2010. "Learning the Hard Way? European Climate Policy After Copenhagen," Environment: Science and Policy for Sustainable Development, 52(3): 20-27.

Hovi, Jon, Tora Skodvin, and Stine Aakre. 2013. "Can Climate Negotiations Succeed?” Politics and Governance, 1(2): 138-150.

Keleman, R. Daniel and David Vogel. 2009. "Trading Places: The Role of the United States and the European Union in International Environmental Politics," Comparative Political Studies, 43(4): 427-456.

Mabey, Nick, Liz Gallagher and Camilla Born. 2013. "Understanding Climate Diplomacy: Building diplomatic capacity and systems to avoid dangerous climate change," $E 3 G$, October.

May, Peter J. 1992, “Policy Learning and Failure,” Journal of Public Policy 12(4): 331-354. p. 339. 
Nelsen, Arthur. 2015. "EU to launch diplomatic offensive ahead of Paris climate talks," The Guardian, 20 January 2015.

Nye, Joseph. 2011. The Future of Power. PublicAffairs.

Oberthur, Sebastian. 2011. “The European Union’s Performance in the International Climate Change Regime," European Integration, 33(6): 667-682.

Peters, Jonathan. 2015. "From principals to pragmatism? The changing use of narratives in the EU's climate diplomacy," MA Thesis College of Europe.

Riddervold, Marianne and Akasemi Newsome. 2018. “Transatlantic Relations in times of Uncertainty: Crises and EU-US Relations," Journal of European Integration, this issue.

Schafhausen, Franzjosef. 2015. Director General, Federal Ministry of Environment, Building and Nuclear Safety, Germany, EU Pavilion at COP 21, "Practitioners Panel: Learning from INDC preparations and accelerating implementation after Paris, December 8.

Schaik, Louise van, “The Sustainability of the EU's Model for Climate Diplomacy,” in Oberthur, Sebastian and Marc Pallemaerts, The New Climate Policies of the European Union: Internal Legislation and Climate Diplomacy, VUB Press, 2009

Schaik, Louise van and Simon Schunz. 2011. "Explaining EU Activism and Impact in Global Climate Politics: Is the Union a Norm- or Interest-Driven Actor?” Journal of Common Market Studies, 50(1): 169-186.

Sjursen, Helene. 2017. "Global Justice and Foreign Policy: The Case of the European Union," GLOBUS Research Papers, February-May.

Torney, Diarmuid. 2013. “European Climate Diplomacy: Building Capacity for External Action,” The Finnish Institute for International Affairs Briefing Paper 141, October 2013. 
Vogel, David. 2012. The Politics of Precaution: Regulating Health, Safety, and Environmental Risks in Europe and the United States, Princeton University Press

Panel at EU pavilion, COP 21, December 7, 2015.

Urban Low Emission Development Strategies, "Cities in Action - Update 2015: Low Emission Development in Brazil, India, Indonesia and South Africa.” 